\title{
Cambiemos la historia. Una creación hipertextual basada en las TIC
}

Número 5.

Enero de 2016

\author{
María Marco Martínez \\ Darío Bañón Olivares
}

Universidad de Murcia
Pág. 36 a la 43

Keywords

hypertext, ICT, traditional literature, music

\begin{abstract}
:
The historical chronology shows a narrow intertextual link between literature and music, present in various cultural and artistic contexts. It is essential, therefore, employment and use of educational skills as the main approach to promoting reading habit among students.
\end{abstract}

Through to ICT and the area of Arts Education can develop an active methodology where standards and focused on the understanding and the promotion of reading fiction in the area of Spanish Language and Literature contents are worked, thus promoting creativity and autonomy in students through meaningful learning that contributes to the development of the learners.
The draft is based on a teaching experience of hypertext creation aimed at students in 5th year of Primary Education (2nd Tranche), where classical literature (folktales) merges with the ternary musical form (ABA), the point starting from a narrative and musical invention which is reflected in ICT tools through different program used for editing and mounting. This is intended also to demonstrate the similarity between the structure and organization which keep the literary and musical patterns. 



\section{Las TIC en Educación Primaria}

"Los constantes cambios y evolución de la sociedad respecto al uso de las tecnologías en general, y en el ámbito educativo en particular, están potenciando el hecho innegable de que es importante un uso de las TIC en la escuela, con coherencia y bien enfocado hacia una práctica efectiva" (Sáez, 2012). Las nuevas tecnologías se sitúan en uno de los primeros puestos de conocimientos fundamentales que debe adquirir la sociedad actual para lograr un desarrollo cultural pleno, ocupando el presente más concreto y acaparando nuestro entorno como forma de comunicación enfocada a diversos niveles que generan estímulos receptivos. Por ello, es conveniente fomentar su uso desde una perspectiva educativa y formal en edades tempranas, ya que "con el uso de las tecnologías, las representaciones del conocimiento y la información se transforman" y "hacen posible representar la información en forma variada combinando formas textuales con formas gráficas, animadas y sonoras, con el fin de llevar mensajes claros y mostrar las relaciones entre conceptos mediante esquemas y estructuras apropiadas" (Ospina Pinera, 2003). Dicha combinación metodológica ofrece a los discentes gran cantidad de recursos y posibilidades para favorecer la motivación educativa.

El eje fundamental de este proyecto está basado en fomentar la lectoescritura en el alumnado de $5^{\circ}$ curso de Educación Primaria (segundo tramo) a través de contenidos y estándares musicales del área de Educación Artística que, con herramientas TIC, logren potenciar el hábito lector hacia la literatura tradicional.

Se halla a lo largo de la historia, una estrecha relación entre las obras literarias y musicales basadas en la intertextualidad. Por ello, podemos observar la conclusión llevada a cabo a través del estudio de la doctora de Vicente-Yagüe (2012) donde afirma que "la aplicación en el ámbito de la enseñanza de la Literatura de un modelo didáctico interdisciplinar, basado en el estudio de referentes intertextuales musicales permite el desarrollo de actividades innovadoras en el aula". Esto conlleva al desarrollo del hábito lector de los discentes, así como a la interpretación del sentido de la obra literaria y el conocimiento sobre estructuras internas de creaciones. Por ello, la unión entre la literatura y la música en contextos escolares y "de manera conscientemente simbólica, lleva al alumnado hacia conceptos de apertura de nuevas culturas, nuevos diseños de trabajo, de esfuerzo, con el ingrediente de la interdisciplinaridad y la intertextualidad" (Guerrero, 2008), provocando así un desarrollo cognitivo globalizado de ambas áreas (Ed. Artística y Lengua Castellana y Literatura) donde a través del concepto de hipertextualidad crean conexiones interrelacionadas entre ellas a través de la literatura (Genette, 1982).

La similitud estructural (anteriormente mencionada) entre los esquemas musicales y literarios, deja patente un legado histórico que podemos continuar en el presente. Así, partiendo de la estructura establecida en el Clasicismo de la forma sonata (Diccionario Harvard de la Música, 2008) podremos trabajar la exposición (donde se exponen los temas), el desarrollo (donde se trabaja con los temas de la exposición) y la reexposición (reitera la

Marco Martínez, M y Bañón Olivares, D (2016): Cambiemos la historia. Una creación hipertextual basada en las TIC, Investigaciones Sobre Lectura, 5, 36-43. 
exposición) (Ulrich, 2004), a través de la creación literaria, definida bajo unos parámetros donde van a estar presente los cuentos populares, puesto que "los esquemas narrativos tradicionales deben ser enriquecidos [...] por medio de nuevos códigos que pretendan distintos acercamientos al hecho literario" (de Vicente-Yagüe, 2014)

\section{Desarrollo curricular}

El diseño innovador didáctico presentado a continuación, se rige por el Decreto $\mathrm{n}^{\mathrm{o}}$ 198/2014, de 5 de septiembre, por el que se establece el currículo de la Educación Primaria en la Comunidad Autónoma de la Región de Murcia, más concretamente de nuestras áreas específicas: Educación Artística y Lengua Castellana y Literatura. Los contenidos destinados a $5^{\circ}$ curso de Educación Primaria ( $2^{\circ}$ tramo) de ambas áreas anteriormente mencionadas que se trabajan en dicha experiencia didáctica, son los siguientes:

\section{Educación Artística}

\section{Contenidos:}

Bloque 1: Escucha

- Los instrumentos musicales.

- Reconocimiento visual y auditivo de los instrumentos trabajados y clasificación en familias y subfamilias viento, cuerda y percusión.

- Grabación digital de la interpretación creada.

- Forma musical: binaria $(\mathrm{AB})$, ternaria $(\mathrm{ABA})$ y rondó.

Bloque 2: La interpretación musical

- Discriminación auditiva de pequeños fragmentos melódicos.

- Creación de piezas musicales sencillas utilizando las tecnologías de la información y la comunicación.

\section{Estándares de aprendizaje:}

Bloque 1: Escucha

- $\quad 2.1$ Reconoce en una audición sencilla pequeñas variaciones y contrastes de velocidad e intensidad, así como instrumentos que intervienen.

- 2.3 Clasifica visual y auditivamente los instrumentos estudiados, en sus respectivas familias.

- $\quad 2.6$ Identifica formas musicales sencillas.

Bloque 2: La interpretación musical

- $\quad 1.4$ Crea esquemas rítmicos y melódicos con los esquemas trabajados.

- 1.6 Interpreta pequeñas piezas instrumentales de forma aislada o como acompañamiento a canciones o audiciones. 
- $\quad 2.2$ Utiliza los medios audiovisuales y recursos informáticos para crear piezas musicales y para la sonorización de imágenes y representaciones dramáticas.

Bloque 3: La música y la danza

- $\quad 1.1$ Identifica el cuerpo como instrumento para la expresión de sentimientos y emociones y como forma de interacción social.

Lengua Castellana y Literatura:

\section{Contenidos:}

Bloque 1: Comunicación oral: hablar y escuchar

- Estrategias y normas para el intercambio comunicativo: participación; exposición clara; organización del discurso; escucha; respeto al turno de palabra; papel de moderador; entonación adecuada; respeto por los sentimientos, experiencias, ideas, opiniones y conocimientos de los demás.

- Debates, coloquios, entrevistas, etc.

Bloque 2: Comunicación escrita: leer

- Lectura de distintos tipos de texto: descriptivos, argumentativos, expositivos, instructivos, literarios.

- Uso de las TIC

Bloque 3: Comunicación escrita: escribir

- Uso de las TIC. Estrategias de uso y tratamiento de la información: toma de notas, esquemas, etc. Procesador de textos, creación de carteles, cómic, anuncios, etc.

Bloque 5: Educación literaria

- Lectura guiada de textos narrativos de tradición oral, literatura infantil, adaptaciones de obras clásicas y literatura actual.

- Creación de textos literarios en prosa o en verso, valorando el sentido estético y la creatividad: cuentos, poemas, adivinanzas, canciones, y teatro.

\section{Estándares de aprendizaje:}

Bloque 1: Comunicación oral: hablar y escuchar

- 1.3. Aplica las normas socio-comunicativas: escucha activa, espera de turnos, participación respetuosa, adecuación a la intervención del interlocutor y ciertas normas de cortesía.

- 2.1 Participa en actividades de comunicación en el aula (debates, diálogos, exposiciones...). 
Bloque 2: Comunicación escrita: leer

- 9.1. Sabe utilizar las TIC para buscar información.

Bloque 3: Comunicación escrita: escribir

- 8.1 Utiliza las TIC como recurso para la realización de tareas diversas como escribir y modificar un texto, crear tablas y gráficas, hacer una presentación, etc.

Bloque 5: Educación literaria

- 2.1 Realiza lecturas guiadas de textos narrativos de tradición oral, literatura infantil, adaptaciones de obras clásicas y literatura actual.

- 4.1 Crea textos literarios (cuentos, poemas, canciones y pequeñas obras teatrales) a partir de pautas o modelos dados utilizando recursos léxicos, sintácticos, fónicos y rítmicos en dichas producciones.

Además, dicho proyecto de creación hipertextual, contribuye al desarrollo de las competencias clave, principalmente al desarrollo de la competencia en comunicación lingüística, la competencia digital y las competencias sociales y cívicas.

\section{Diseño de la actividad}

Este proyecto de innovación didáctica está destinado al alumnado de $5^{\circ}$ curso de Educación Primaria (segundo tramo). La temporalización previa de dicha propuesta, sería de cinco sesiones completas que se desarrollarían en el Área de Educación Artística.

El esquema principal está formado por cuatro grandes tareas:

1. Elección y variación del cuento seleccionado (Perrault)

2. Incorporación y asociación de efectos sonoros al cuento

3. Grabación

4. Montaje multimedia

Para fomentar el trabajo cooperativo y el diálogo, todas las actividades propuestas se realizarán en grupos de cinco componentes. El docente actuará como guía y promoverá en todo momento la propia autonomía del alumnado y de los propios grupos formados. Cuando la actividad final de cada grupo quede realizada, el docente mostrará en el blog de aula el resultado, donde se procederá a un concurso en el que podrán votar todos los docentes primando la propuesta más original e innovadora. Esto se le comunicará a los discentes desde un principio para promover su motivación y esfuerzo en las tareas.

La actividad pretende unir esquemas literarios y musicales. En este caso, hemos elegido el esquema del cuento (introducción-desarrollo-desenlace) con la estructura ternaria de la forma sonata (A-B-A). Los discentes deberán recurrir a los cuentos de

ISL, vol. 5, 2016, págs. 36-43 ISNN: 2340-8685
Marco Martínez, M y Bañón Olivares, D (2016): Cambiemos la historia. Una creación hipertextual basada en las TIC, Investigaciones Sobre Lectura, 5, 36-43. 
tradición popular de Perrault para localizar su estructura y dar forma inventiva al desarrollo y desenlace, amoldándose así al comienzo descrito y omitiendo el desarrollo y desenlace original por completo. La extensión máxima será de una página y la elección del cuento popular de Perrault será libre.

Conseguimos con ello que el alumnado tenga una secuenciación real del cuento y una idea más clara sobre la distinción de la estructura musical ternaria (obviamente, la labor del profesor también será la de poner audiciones y hacer comparaciones directas mediante este método de aprendizaje, no sólo con dicha actividad). Todas las sesiones serán desarrolladas en el Aula Plumier del centro.

\section{Sesión 1:}

- El docente dará las pautas anteriormente referidas y los discentes (por equipos previamente asignados) elegirán a través de una exhaustiva búsqueda multimedia el cuento de Charles Perrault que van a trabajar.

- Posteriormente, cada grupo procederá a la invención del desarrollo y desenlace del cuento elegido.

\section{Sesión 2:}

- El docente hará un breve repaso de las familias instrumentales centrándose en los instrumentos de percusión determinada e indeterminada. Los discentes deberán elegir cuatro instrumentos de pequeña percusión y diseñar efectos sonoros para poder introducirlos en sus creaciones (el docente habrá corregido previamente entre una sesión y otra las invenciones literarias creadas por el alumnado a partir de la introducción de los cuentos elegidos). Además de la percusión instrumental, podrán utilizar percusión corporal y sonidos guturales para añadir "otros efectos" a sus creaciones.

- Los discentes buscarán información relevante sobre los instrumentos de pequeña percusión elegidos en cada grupo (procedencia, tipología, peculiaridades...) y realizarán un sencillo Power Point con imágenes y textos descriptivos de cada uno de ellos.

\section{Sesión 3:}

- Cada grupo realizará una breve exposición sobre la información recabada de los cuatro instrumentos de pequeña percusión elegidos para la banda sonora de su cuento.

- Los discentes organizarán y añadirán efectos sonoros a su creación literaria (pueden añadir, además de los instrumentos de pequeña percusión como hemos mencionado anteriormente, percusión corporal y sonidos guturales) 
- Antes de finalizar la sesión, leerán a sus compañeros sus cuentos con los efectos sonoros correspondientes (cada alumno desempeñará un papel diferente, quedando elegido un narrador y cuatro percusionistas).

\section{Sesión 4:}

- El alumnado, a través de sus respectivos grupos, procederá a buscar imágenes (un número máximo de cinco láminas por creación literaria). Previamente, el docente facilitará la herramienta para la búsqueda de imágenes con Lincencia Creative Commons.

- Por turnos grupales y bajo la supervisión continua del docente, se grabará el audio de sus cuentos (voz y efectos sonoros). El programa de audio que se utilizará, será un editor de audio libre de código abierto, en el que no repararemos en explicaciones técnicas a los alumnos, pues será manejado por el docente. Dicho programa es Audacity 1.3 Beta descargado de la página www.softonic.com, que ofrece programas gratuitos (entre otros).

\section{Sesión 5:}

- Cada grupo de discentes editará un vídeo a través del software Window Movie Maker, donde aparecerá el audio y las imágenes buscadas en la sesión anterior, además del título y alguna cortina o diseño que disponga dicho software. Para ello, el docente dará una explicación breve sobre el funcionamiento de dicho software y les facilitará el audio.

- Visualización de la tarea final

- Debate

\section{Reflexión final}

La elaboración y planificación del proyecto de creación hipertextual anteriormente desarrollado, mantiene el objetivo principal de fomentar la actitud literaria del alumnado a través de esquemas musicales prefijados, lo que permite aplicar ambas estructuras en un sentido inverso que abarca diversos aspectos: promover la creatividad del alumnado así como el concepto total de libertad de ideas en cuanto a la elección de elementos: cuento, instrumentos, efectos sonoros... para lograr un desarrollo integral del pensamiento crítico.

Finalmente, para promover dicha motivación ya no sólo a nivel de aula o de proyecto, sino de una manera más globalizada en la etapa de Educación Primaria, se prevé hacer público el resultado final del proyecto en el blog de aula, promoviendo así el uso adecuado de las TIC con fines educativos, dando la opción al mismo tiempo, de ser visualizada y comentada libremente por miembros pertenecientes a la enseñanza. 


\section{Bibliografía:}

CARM (2014). Decreto 198/2014, de 5 de septiembre, por el que se establece el currículo de Educación Primaria en la Comunidad Autónoma de la Región de Murcia. (BORM, 6/9/2014)

De Vicente-Yagüe Jara (2014). Un nuevo enfoque de la lectura musical. Análisis literario, musical y didáctico del cuento Mi madre la Oca. Investigaciones sobre lectura, 2, p. 15-23.

Diccionario Harvard de la Música (2008). Madrid: Alianza Editorial.

Genette, G. (1982). Palimpsestes. La littérature au second degré. París: Seuil.

Guerrero, P. (2008). Metodología de investigación en Educación Literaria. (El modelo Ekfrástico). Murcia: Diego Marín.

LOMCE (2013). Ley Orgánica 8/2013, de 9 de diciembre, para la Mejora de la Calidad Educativa.

Ospina Pinera, D. P. (2003). En-torno a la escritura hipertextual. Integración de tecnologías de la información y la comunicación a la docencia. Universidad de Medellín. Colombia http://docencia.udea.edu.co/vicedocencia/

Perrault, Ch. (2000). Todos los cuentos. Alicante: Aguaclara.

Sáez, J. M. (2012). Valoración del impacto que tienen las TIC en educación primaria en los procesos de aprendizaje y en los resultados a través de una triangulación de datos. Revista Latinoamericana de Tecnología Educativa, 11 (2), p. 11-24.

Ulrich, M. (2004). Atlas de música II. Madrid: Alianza Atlas.

Vicente-Yagüe, Ma I. de (2012). La educación literaria y musical. Un modelo interdisciplinar de innovación didáctica en Educación Secundaria, Bachillerato y Enseñanzas Artísticas de Música. Tesis Doctoral, Universidad de Murcia.

Marco Martínez, M y Bañón Olivares, D (2016): Cambiemos la historia. Una creación hipertextual basada en las TIC, Investigaciones Sobre Lectura, 5, 36-43.
ISL, vol. 5, 2016, págs. 36-43 ISNN: 2340-8685 